\title{
MODERNIDAD Y REPRESENTACIÓN AFROCUBANA EN REVISTAS ILUSTRADAS DE 1915 A 1940 EN CUBA
}

\author{
POR \\ Jorge Catalá Carrasco \\ Newcastle University
}

\section{INTRODUCCIÓN}

Quisiera comenzar con una imagen publicada en el periódico cubano El Mundo el 30 de septiembre de 1918. Una mujer y su mascota son los pasajeros en un automóvil conducido por un hombre vestido con la indumentaria propia de un chofer. El año de su publicación coincide además con la aprobación de la ley de divorcio en Cuba. En la parte inferior de la imagen, una frase refuerza el mensaje icónico que se articula en función de un deseo: "parece imposible, pero es verdad. Un carro LEXINGTON en $\$ 1,900$ ". Sin tratarse de un Ford, ${ }^{1}$ la marca de automóviles Lexington estaba llegando a su momento cumbre de producción y en 1918 produjo más de 4,000 vehículos. La imagen es, por supuesto, un anuncio publicitario para la venta del producto manufacturado que condensaba buena parte de los cambios sobrevenidos con el advenimiento de la modernidad. Y Cuba era compradora privilegiada de dichos productos, habida cuenta de su proximidad geográfica con los Estados Unidos y de la relación entre ambos países. El medio en el que se publicó, el periódico El Mundo (1901-1969), ejemplifica esta adaptación de la prensa periódica a los cambios de índole tecnológico y estético-comunicativo entrado el siglo XX. Como ha destacado el investigador en comunicación Jorge Bermúdez, El Mundo fue el primer periódico de la modernidad en desarrollar el nuevo periodismo en Cuba:

Introducción de los avances tecnológicos en los medios de impresión, lo que redundará en una más adecuada presentación y jerarquización de la información, así como del buen uso de los recursos gráficos de carácter estético-comunicativos; aumento del número de páginas y variedad de temas informativos, mayor inmediatez

\footnotetext{
1 Ya para el año 1919, la empresa Ford Motor Company producía el 50\% de los automóviles en los Estados Unidos. "Los 'fores', como se les llamó, ocuparán su espacio en el mercado y en la vía, justo cuando empieza un periodo de bonanza para la economía cubana, que se bautizó con la muy rural imagen de Vacas Gordas" (Bermúdez 66).
} 
y difusión de los mismos en el ámbito nacional e internacional; reelaboración de la noticia con un sentido creativo, y acentuación de las diferencias entre columnistas y editorialistas (Bermúdez 42).

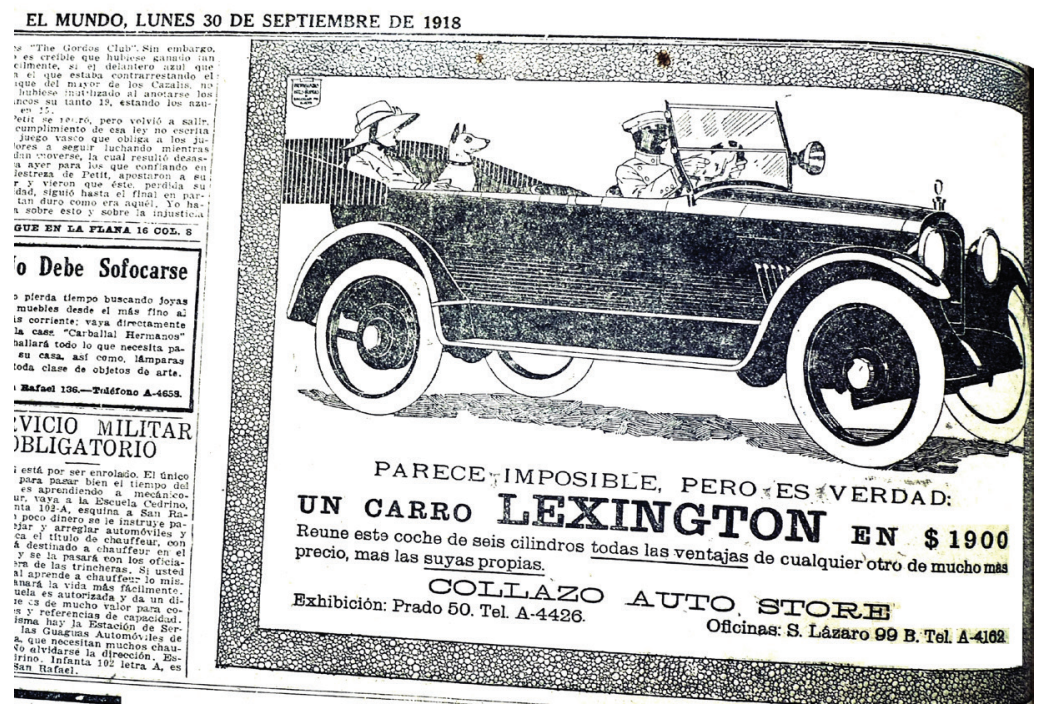

Un último detalle es que el conductor del carro es negro. Acaso una versión acorde a los nuevos tiempos del calesero del siglo XIX, una profesión desarrollada fundamentalmente por la población negra que conllevaba un estatus privilegiado dentro del escalafón social de la esclavitud en Cuba hasta su abolición. La visibilidad de la población afrocubana en la prensa periódica discurrirá de manera paralela a los avances tecnológicos que facilitaron la incorporación de la gráfica de comunicación (ilustración, diseño gráfico, caricatura e historieta) con fines artísticos y comerciales en la prensa periódica cubana. El uso de imágenes en revistas periódicas se incrementó de manera decisiva durante el siglo XIX como consecuencia de las mejoras en las técnicas de impresión, como la litografía (1796), la cromolitografía (1837) y la prensa rotativa (1843). Pero fue con la llegada de la impresión offset (1875) y la creación de la máquina mimeografiada (1890) cuando periódicos y revistas adquieren un nivel técnico superior y una distribución masiva. Todo ello facilitó un desarrollo de la gráfica durante el siglo XIX que ha dado algunas de las joyas bibliográficas de la cultura cubana e hispanoamericana como Los ingenios (1857), de Justo Germán Cantero e ilustraciones a cargo de Eduardo Laplante. Considerado el libro más caro del siglo en Cuba (Fornet 69), se vendió por entregas de 1855 a 1857. El mismo

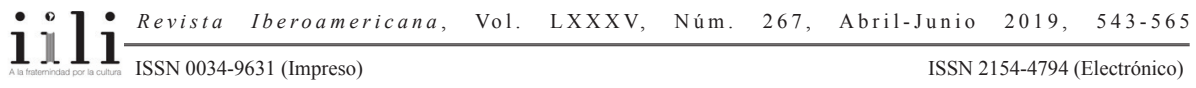


año, Juan Martínez Villergas funda el primer periódico satírico ilustrado en Cuba, $L a$ Charanga.

En la segunda mitad de siglo las marquillas cigarreras acentuaron la vinculación entre la gráfica de comunicación y las estrategias de mercado al decorar las cajetillas de cigarrillos con vistosas litografías que incidieron en temas costumbristas y de sátira social. Las marquillas se editaban en series temáticas que transformaban lo que era fundamentalmente un mecanismo utilitarista de marketing en un objeto de coleccionista (Lugo-Ortiz 124). Muchos de estos cuadros de costumbres contenían jocosas imágenes de negros cubanos, lo que ha llevado a la estudiosa Adelaida de Juan a señalar que la temática negra, lejos de manifestarse inicialmente en la pintura cubana, lo hizo "en los grabadores, especialmente [Hipólito] Garnerey, [Fréderic] Mialhe, [Eduardo] Laplante, [Víctor Patricio] Landaluze, y en las litografías de las cajetillas de cigarros" (citado en Aramburu 12). Precisamente Landaluce será el autor de la obra cimera de finales del XIX en cuanto a ilustración y reflejo social de la sociedad cubana. Me refiero a Tipos y costumbres de la Isla de Cuba (1881), que junto con la novela de Cirilo Villaverde, Cecilia Valdés (1839), son dos textos fundamentales en la indagación de la cubanía y en ambos, como no podía ser de otro modo, la temática negra está necesariamente presente.

$\mathrm{Al}$ adentrarnos en el siglo XX de nuevo la pintura tardará en acometer la labor de representar y dar protagonismo (es decir, hacer partícipe de la creación de la nación) a la población negra. No será hasta entrada la década de 1930, con el redescubrimiento del negro, cuando se empiece a vislumbrar un interés por pintores de la talla de Víctor Manuel o Eduardo Abela, a los que se sumará Wilfredo Lam en la década de 1940. Otro tanto podría decirse con respecto a la vanguardia gráfica que tendrá en la ilustración, el diseño gráfico, la caricatura y la historieta sus mayores y más tempranos exponentes, mucho antes de las primeras incursiones de la plástica cubana.

La tarea que tenía por delante la sociedad cubana, cuando se inaugura la flamante nueva república el 20 de mayo de 1902 era, qué duda cabe, ilusionante a la par que titánica. La liberación del yugo colonial español se había conseguido tras una ardua lucha en la que la guerra de 1895-1898 marcaba su último episodio y la intervención norteamericana en 1898, el indeseable colofón. Pese a las suspicacias de Máximo Gómez, ${ }^{2}$ general en jefe de las fuerzas revolucionarias, respecto a la decisiva intervención militar de los Estados Unidos en Cuba, resultaba evidente para los cubanos que España era atraso, lastre. Los Estados Unidos, progreso, fuelle.

2 En una misiva de octubre de 1898, cuatro meses después de terminada la guerra Hispano-CubanoAmericana, Gómez no oculta su descontento con la nueva situación impuesta tras la intervención estadounidense: "Los cubanos no pueden darnos pan y los Americanos, jah los americanos! Entre ellos y los españoles, aun hecha la paz, nos han obligado á vivir en despoblados como bestias" (citado en Álvarez Pitaluga 140).

$111 \frac{\text { Revista Iberoamericana, Vol. LXXXV, Núm. 267, }}{11}$ Abril-Junio 2019, $\quad$ 543-565 
La creciente influencia norteamericana en Cuba marcará los destinos de la joven república durante las primeras décadas del siglo XX. En lo político, la Enmienda Platt, primero incorporada como ley en los Estados Unidos y acto seguido como anexo a la constitución cubana, otorgará al gobierno de los Estados Unidos la facultad de intervenir en Cuba para salvaguardar el orden y los intereses estadounidenses. La soberanía nacional estaba lejos de haber conseguido una independencia plena y la injerencia del vecino del norte será constante, en forma de intervenciones militares (1898-1902; 1906-1909; 1912; 1917-1923), las más veces, a pedido de las autoridades cubanas.

Mi propósito en este ensayo es analizar el desarrollo de la prensa periódica cubana y la visualización de la población negra o mulata en Cuba desde 1915 a 1940. Otorgaré especial énfasis a la historieta, que despega en Cuba a partir de 1915 en las páginas de Bohemia. Se trata pues de una manifestación cultural gráfica de larguísima tradición en Cuba, que emana de la cultura popular y que como tal se acercó a la calle en su retrato de la sociedad cubana republicana. Es difícil hallar otra producción cultural que haya otorgado más espacio al negro en los inicios del siglo XX en Cuba. La historieta tendrá en sus inicios un claro enfoque costumbrista, en consonancia con una nación que está en pleno periodo de construcción nacional y para la que es esencial reconocerse. Como apunta Stuart Hall, la cultura popular es el terreno en el que se trabajan las transformaciones en una sociedad (Hall 443). El punto de llegada de este recorrido será 1940, año de la nueva constitución en Cuba que específicamente declaró ilegal la discriminación basada en raza, color, género o religión.

En Cuba las revistas ilustradas acercaron los debates de la arena pública al ámbito doméstico. Los cómics, caricaturas e ilustraciones publicados en periódicos y revistas canalizaron, a nivel popular, los grandes debates en torno a la inclusión del negro en la polity. Tanto es así que ejercieron de transmisores de miedos, ansiedades y discriminaciones para, con el tiempo, evolucionar hacia un cambio en la aceptación del negro en el proceso de construcción nacional. En el estilo costumbrista de estos primeros cómics, subyacen las complejas relaciones sociales y el estatus y reconocimiento que los afrocubanos fueron gradualmente ganando en la sociedad cubana. Estas primerizas historietas cubanas a través del día a día, exploran las peculiaridades de la cubanía tal y como se ve y se oye en la calle. Contrariamente a lo sucedido con la música afrocubana, en la que las formas musicales fueron inicialmente elogiadas, pero luego sufrieron un proceso de transformación minimizando su ascendencia africana o sus elementos populares (Moore 1997), en la historieta encontramos un reflejo popular en clave de humor que no necesita enmascarar las cosas. O como dijera Luján, alter ego del intelectual Jorge Mañach, en una de sus populares estampas publicadas en 1926 titulada "La morenita presumida" sobre cómo algunos artistas pintaban a las mujeres afrocubanas igual que a las criollas blancas: "El bronce es bronce, y el oro es oro. No hay que simular..." (Mañach 73). 


\section{LAS REVISTAS: SOPORTES DE LA MODERNIDAD}

Con el nuevo siglo aparecen nuevos periódicos, como El Mundo (1901-1969), que se suman a las revistas ya existentes pero que evolucionan de manera dramática hacia una modernidad en contenidos, diseño gráfico y fidelización de la audiencia. $E l$ Fígaro (1885-1933?) o La Habana Elegante 3 (1883-1891; 1893-1896) son buenos ejemplos de este cambio de tendencia. El Mundo y El Fígaro son las dos publicaciones determinantes de lo que Bermúdez ha llamado el nuevo periodismo cubano: "Algunas de estas características se plasmarán como primicias en El Mundo; notablemente, el uso de tricromías y anuncios publicitarios a color, hacerse todo por impresión mecánica, así como introducir las ocho columnas y la crónica social ilustrada con una periodicidad diaria" (Bermúdez 42).

A las mejoras en las técnicas de impresión y la estilización del lenguaje comunicativo publicitario, cabe añadir el creciente protagonismo del humorismo gráfico en publicaciones periódicas. En el caso de la caricatura, por un lado refleja una evolución desde el dibujo deformativo del XIX hasta un impresionismo en la línea. Rafael Blanco (ilustrador del libro de Mañach Estampas en La Habana en 1926) se encargó de introducir en Cuba la línea impresionista japonesa que partiendo de lo físico intenta captar lo psicológico en el personaje caricaturizado. En este sentido el humorismo gráfico no solo se propone reflejar "lo que ve y lo que oye" sino desentrañar el espíritu, el alma de la persona en cuestión. La caricatura y el humorismo gráfico, parten de la deformación del caricaturizado para proponer transformaciones en la realidad e incluso mejoras en las condiciones sociales de vida. En la historia cultural de este medio hay un sinfín de ejemplos, desde William Hogarth, George Cruikshank o James Gillray y sus caricaturas del rey George III en el siglo XVIII, hasta Gustave Doré o Honoré Daumier y su caricatura del rey Louis Philippe de Francia como el gigante Gargantúa. Como ha destacado Luz Merino:

En el horizonte histórico de los primeros veinte años del pasado siglo se entendía que la caricatura servía de vehículo al humorismo, por la función social y ética, lo que le permitía obrar como un ente transformador. Desde esta perspectiva el humorismo debía hablar a las masas, combatir los prejuicios, errores y comportarse como un factor renovador y un procedimiento democratizador. (66)

3 Subtitulado inicialmente "Periódico bisemanal de noticias interesantes a las señoras y señoritas", se orientó hacia la literatura, como El Fígaro. Dedicó mucho espacio a la publicidad. "Al reaparecer en 1893, fue el órgano de la corriente modernista y se convirtió de lleno en una revista literaria, estimada no solo en Cuba, sino también en Centro y Sudamérica. Su papel y sus grabados fueron de primera calidad" (Diccionario 423).

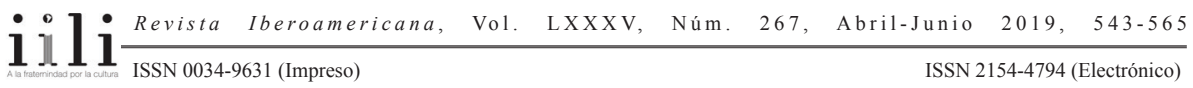


Al ente transformador que postula Merino respecto a la caricatura, cabe añadir el papel de la historieta (que durante estos años presenta un desarrollo en torno al costumbrismo fundamentalmente) como producto cultural que despega a través de la prensa periódica convirtiéndose en un medio de masas y que además representa un nexo de unión con los procesos modernizadores de principios del siglo XX:

First comics can be seen as an outcome of the process of modernization, and second they can be viewed as a humor-based response to the problems of representation faced by a society in transition. As an outcome of modernization comic strips appear as a social phenomenon, in this case one of the first widely consumed commodities produced by emerging mass entertainment industry [...] The comic strip mode of representation, particularly the use of sequential panels and narratives without closure, predated bolder Modernist efforts to reconfigure strategies of representation [...] Comic strips were representations through which an increasingly commodified society saw and constituted itself. (Gordon 6)

La cita de Gordon tiene especial resonancia en Cuba que atravesaba una transición de colonia a república, en pleno proceso de construcción nacional. En este contexto, otra de las publicaciones señeras de la modernidad en Cuba, Bohemia (1910), introduce a partir de octubre de 1915 cambios de formato (incrementa su número de páginas y el tamaño de las mismas) y diseño gráfico ya que decide apostar claramente por el componente visual. Este cambio se anuncia en el n. 39 del 26 de septiembre de 1915 en un artículo titulado "Las reformas de Bohemia", en el que se menciona la próxima aparición de historietas en la revista. En otro artículo del 3 de octubre de 1915 para la misma revista, expresamente se recalca la importancia de la prensa gráfica (fotografía y grabado) e introduce, una apostilla peyorativa sobre aquellos que “gustan solo de hojear al descuido las revistas para ver 'los muñecos' no pueden darse exacta cuenta de la importancia en el orden cultural que estas publicaciones tienen" (Alemán s/p).

La expresa declaración marca una nueva tendencia en Bohemia en la que el apartado gráfico tendrá capital importancia pero a la vez confirma la pujanza del humor gráfico, la caricatura y también tímidamente de la historieta en la prensa gráfica del momento. La censura del autor del texto sobre aquellos que gustan solo de hojear al descuido "los muñecos" confirma un hábito lector. En definitiva, el proceso de adaptación de la imagen a una prensa periódica renovada que paulatinamente incorpora el reclamo comercial de la publicidad, discurre en paralelo al establecimiento definitivo de la tira de prensa de corte humorístico y a su utilidad para fidelizar lectores. La crítica literaria Annie Russell Marble identificó este cambio de costumbres en la sociedad estadounidense en un visionario artículo para The Dial, el primero de noviembre de 1903, titulado "The Reign of the Spectacular": "the

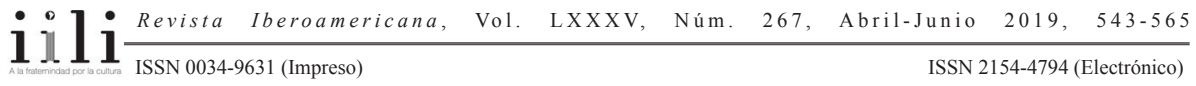


literature that is episodic and pictorial, gains the popular favor. The eye of the senses is regnant, -often a substitute for ear, imagination, and reason" (Marble 7). Marble observó el interés por parte del público lector en una literatura que internalizaba la experiencia del folletín europeo y proponía una manera alternativa de llegar al lector a través de las revistas ilustradas. La prevalencia de la imagen, según Marble, opera como un sustituto de la imaginación. En este sentido, la historieta (o los muñecos, término popularizado en Cuba) va a encapsular esta nueva era al tratarse de un medio episódico (organizado en viñetas sobre las que opera una secuencia) y pictórico (el dibujo se liberará gradualmente de su subordinación del texto que lo acompaña).

\section{BOHEMIA Y LA REPRESENTACIÓN DE LA AFROCUBANÍA}

La historieta anunciada en el artículo de Bohemia en octubre de 1915 comenzó a publicarse a partir de ese mismo número de manera ininterrumpida hasta 1922. Llevaba por título "Aventuras de Pepito y Rocamora" y venía firmada por Peter Relav, seudónimo del dibujante y editor gráfico Pedro Valer. Similares experiencias se estaban dando en otros contextos de América Latina como es el caso de Argentina, con la publicación de "Las Aventuras de Viruta y Chicharrón" a partir del 27 de abril de 1912 en las páginas de Caras y Caretas. En el caso de México, "Don Lupito" de Andres Audiffred en 1903 es considerada la primera tira cómica. En Chile, fue "Federico Von Pilsener" en la Revista Zig-zag en 1906 y en Perú los primeros ejemplos de historietas se encuentran en la revista modernista Monos y Monadas de 1905 a 1907 (Catalá-Carrasco, Drinot y Scorer, Comics and Memory).

El caso de "Pepito y Rocamora" es significativo porque además de ser el primer cómic cubano publicado de manera seriada en una revista del prestigio de Bohemia, nos ofrece al mismo tiempo un cuadro costumbrista de la sociedad cubana de principios del siglo XX, con un especial protagonismo de Rocamora, que se autodefine como "el negrito de la bulla, el moreno Rocamora". La prolongada vida de la historieta (siete años) es una indicación de la positiva respuesta por parte del público lector, quizá debido a la combinación del mencionado enfoque costumbrista y un estilo y temáticas cómicas, basadas en situaciones slapstick que ya habían demostrado ser un reclamo poderoso entre la audiencia norteamericana. "Pepito y Rocamora" representa una nueva generación que entra en la edad adulta y que busca su lugar en la nueva sociedad cubana. Pero también es una reflexión humorística del conflictivo estado en el que se encontraba el mercado de trabajo con el nacimiento de la república en $1902 .{ }^{4}$

4 En la huelga de aprendices de 1902 los cubanos intentaron apropiarse todos los trabajos de la industria tabaquera (Pérez 162). En 1907 los estibadores, trabajadores de la construcción y de la industria tabaquera protestaron contra el sistema por el cual los salarios se entregaban en billetes españoles mientras que los bienes de consumo se vendían en dólares (Pérez 153).

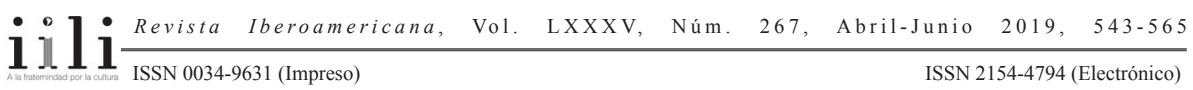


En 1914 tuvo lugar el Primer Congreso Nacional de Trabajadores que reunió en La Habana a 1,700 delegados y aprobó una serie de medidas como la necesidad de una ley de nacionalización del trabajo, jornada de ocho horas y una reducción del coste de vida. En esta década de 1910 las huelgas reverberaban en todo el país (Pérez 153). Si nos centramos en el personaje de Rocamora, podemos conocer cuáles eran los trabajos aceptables para los afrocubanos, como el mencionado oficio de conductor, tal y como vimos en el anuncio publicado en El Mundo y que también se trata en la historieta del 5 de diciembre de 1915. Mientras Pepito probará suerte en diversos oficios como ayudante de farmacéutico o de sastre, Rocamora se desempeñará como chico de los recados o se cosificará en maniquí, tal y como sucede en la historieta del 17 de octubre de 1915. En este ejemplo, Rocamora se verá obligado a permanecer inmóvil como un maniquí tras probarse varias prendas de ropa y así evitar ser descubierto. Cuando el dueño acuerda la venta de las prendas y los modelos, Rocamora piensa en un pasado no tan lejano: "Pues no me ha vendido el sastre como si estuviéramos todavía en los tiempos de la esclavitud!" En efecto, la abolición de la esclavitud en Cuba todavía era un hecho relativamente reciente para la población afrocubana ya que se produjo en 1886. Cuba fue el penúltimo país en América Latina en abolir la esclavitud, seguido de Brasil que lo hizo en 1888.
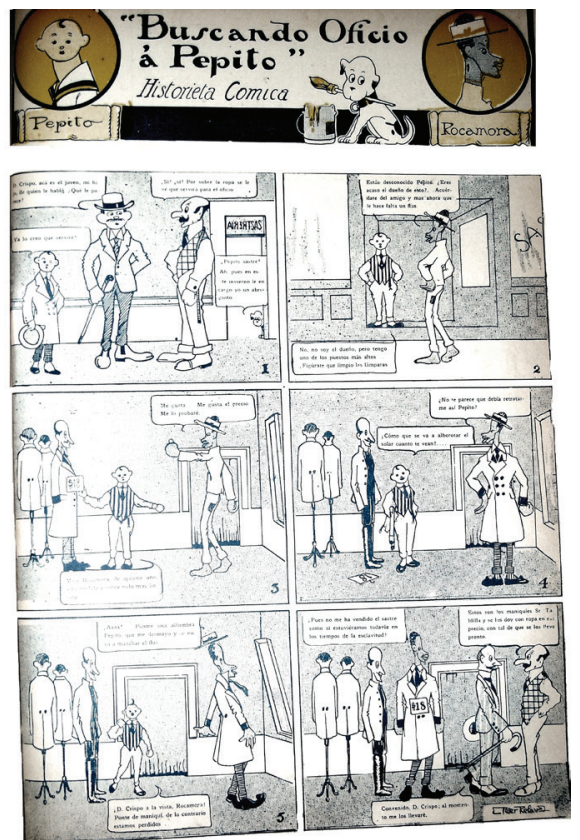

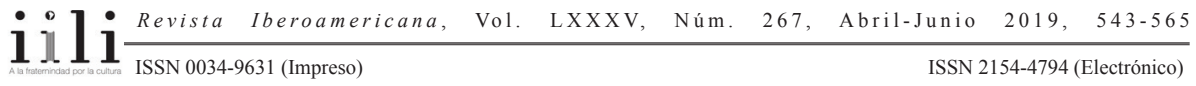


Como apunta Pérez Jr.: "The premise of Cuba as civilized could not easily accommodate the presence and participation of hundreds of thousands of people of African origin [...] Africa was seen as a threat to the endurance of nationality. Spain was backward, Africa was primitive" (90). Por lo tanto, estas profesiones recogidas en una historieta cómica para la revista ilustrada más importante del momento en Cuba señalan el grado de visibilidad que los afrocubanos disfrutaban a comienzos de siglo y más específicamente hasta qué punto se traducía en una creciente igualdad social. Si lo africano se consideraba primitivo (en definitiva, incivilizado) Rocamora siempre se desempeñará en profesiones que impliquen un trabajo manual, acorde a este prejuicio. Como regla general, los oficios de Rocamora siempre estarán un paso atrás en el escalafón social con respecto a Pepito y coincidirán con el censo oficial cubano sobre sectores económicos y oficios. La frecuencia de personajes afrocubanos en las historietas publicadas en la prensa periódica cubana de principios de siglo revela el alto grado de concentración urbana de la población afrocubana. En las primeras décadas del siglo XX el desplazamiento demográfico desde las zonas rurales a las urbanas fue constante y hacia 1943 el $44 \%$ de los afrocubanos vivían en centros urbanos de al menos 5,000 personas, comparado con un 37\% de los blancos (Fuente 110). Este hecho ha llevado a Alejandro de la Fuente a considerar el proceso como una proletarización de los cubanos debido a las agresivas inversiones que desde los EE.UU. se realizaron para comprar tierras en la Isla, combinado con la insolvencia de los propietarios cubanos.

\section{CARTELES: MASSAgUer y LA MODERNIDAD}

Otra de las revistas ${ }^{5}$ señeras de la Modernidad en Cuba fue Carteles (1919-1960), "el primer semanario a escala mundial en imprimirse por el sistema fotolitográfico (offset), adelantándose a los Estados Unidos e Inglaterra, que todavía tardarían cerca de dos años en ensayar y definitivamente adoptar este sistema de impresión" (Bermúdez 103).

Es importante detenerse en Carteles por tratarse de una de las revistas que pondrá en marcha Conrado Massaguer, figura esencial en el despegue de las revistas ilustradas de principios del siglo XX en Cuba. Massaguer influido por las innovaciones técnicas y estéticas que se desarrollaban en los EE.UU. se encargó de desarrollar las potencialidades comunicativas y estéticas del anuncio comercial. Un ejemplo de esta integración orgánica se daría en la historieta "Mango Macho", obra de Horacio, que se publicó desde febrero de 1932 hasta entrado 1933. En el ejemplo

Por razones de espacio, no se analiza la revista Social, revista fundamental como vehículo de expresión del grupo minorista en Cuba. Para más información sobre esta revista ver Bermúdez, Massaquer, República y Vanguardia 71-184 y Lobo Montalvo et al., The Years of "Social" 104-31.

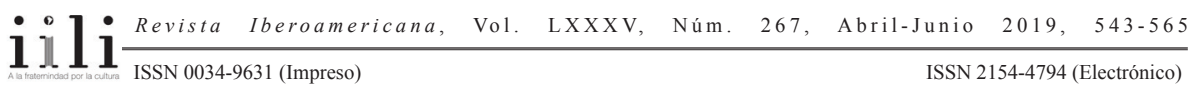


del 11 de diciembre de 1932, podemos ver cómo un par de anuncios se combinan en la historieta cómica: los espejuelos Otero y Artime. Reportes litográficos artísticos. La inclusión de estos dos anuncios se realiza en lo que parece ser un muro o cercado de la calle por la que corre Mango Macho, perseguido por un policía.

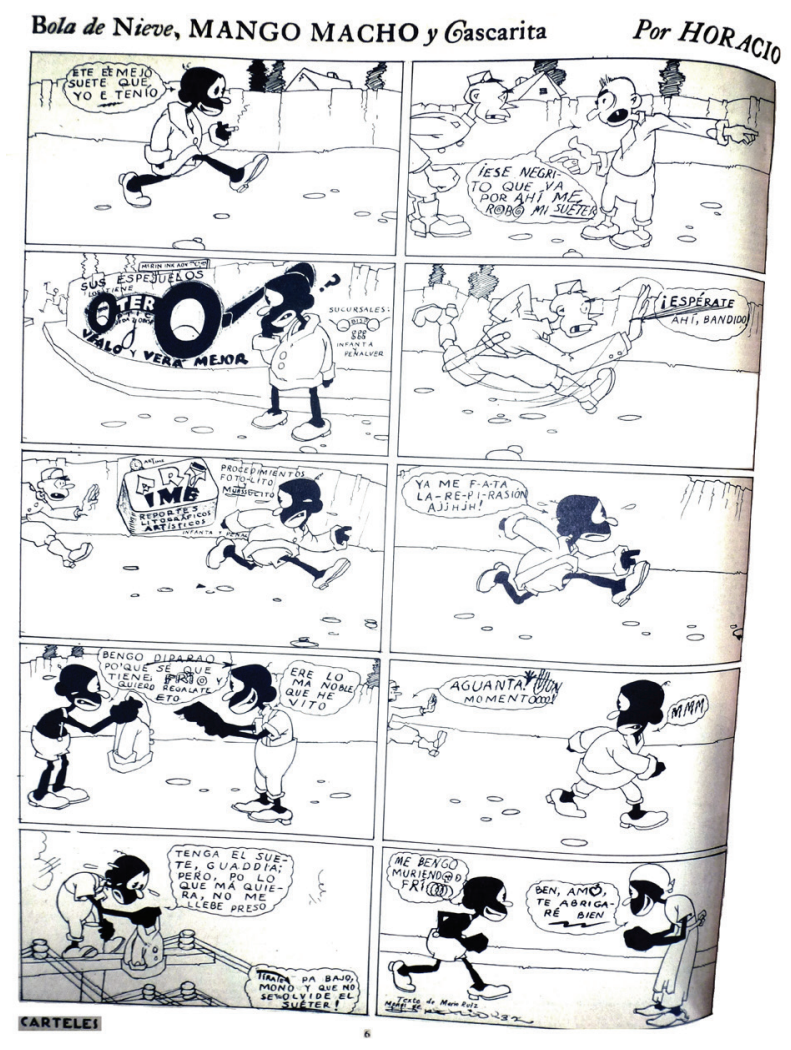

El anuncio es incorporado plenamente a la ficción humorística de la historieta que sirve de gancho para captar a nuevos clientes.

Es evidente que en este contexto se estaban dando pasos decisivos en las artes a través del movimiento afrocubano para incorporar a la población negra en la construcción de la nación. Prueba de ello es la exposición del dibujante y caricaturista Heriberto Portell Vilá inaugurada en febrero de 1932 y recogida en las páginas de Carteles: "Portell, en la línea, como Guillén, en el verso y Lecuona, en la música, ha encontrado motivo de feliz inspiración en los intérpretes del folklorismo afrocubano" (Carteles 21 feb. 1932: 23). Pero al mismo tiempo el desarrollo del anuncio comercial en las revistas ilustradas también fue pasto de los acendrados prejuicios

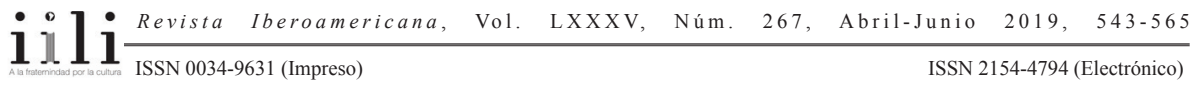


que existían respecto a la población afrocubana, tal y como puede comprobarse en el anuncio de un dentífrico que apareció en Carteles el 22 de mayo de 1932.

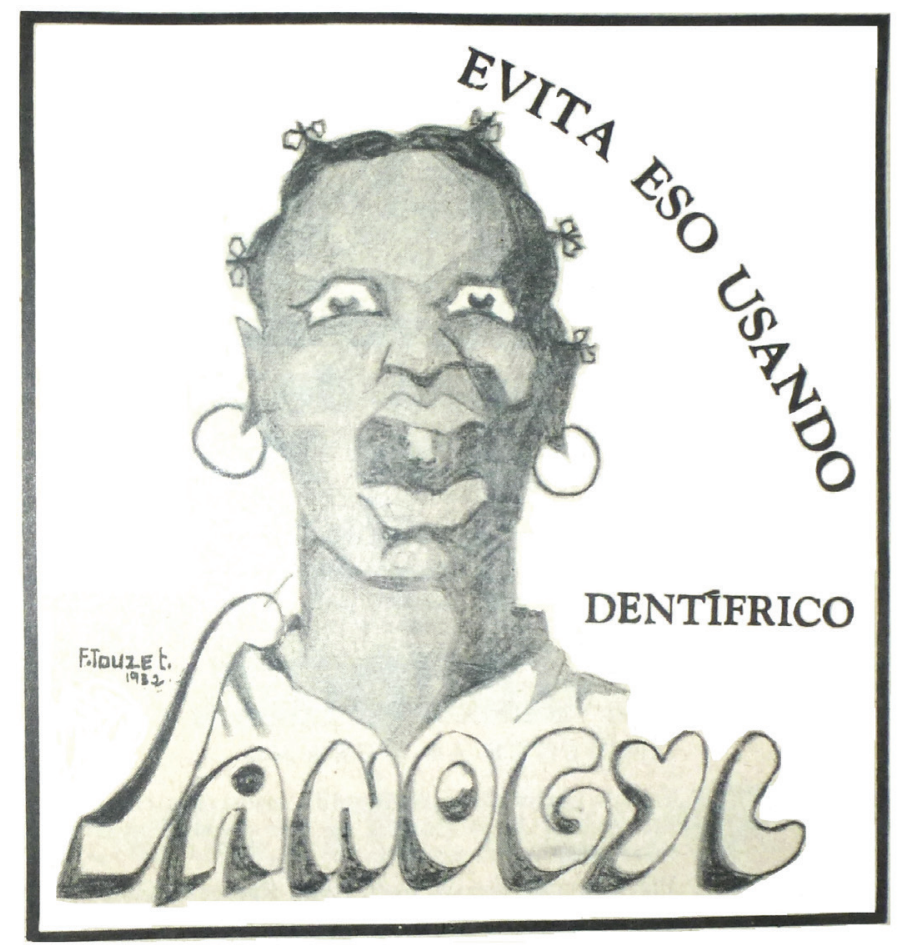

La inclusión de este dibujo para acompañar el anuncio publicitario se realiza con total naturalidad, pese a la extrema composición del mismo, que retrata a la persona en cuestión cuasi en estado de barbarie. El dibujo representa una versión extrema de los estereotipos basados en la raza y la educación pero que, sin embargo, plantea algunas dudas. En cuanto a la educación, la ocupación estadounidense de 1898 a 1902 llevó a cabo mejoras sustanciales en el ámbito educativo llegando incluso a introducir el inglés como lengua vehicular aunque sin éxito (Iglesias 2003). Las diferencias entre mujeres afrocubanas y blancas que sabían leer, teniendo en cuenta los datos del censo de 1907 son prácticamente inexistentes con un 70\% para cada grupo de población. Si tomamos como referencia el censo de 1943, el 67\% de las adolescentes afrocubanas de 10 a 19 años sabía leer, frente al 71\% de las muchachas blancas, lo que supone una diferencia de cuatro puntos, que tampoco representa una margen sustancial. Si se amplía el tramo a mujeres mayores de 20 años las diferencias son similares, $71 \%$ y $74 \%$ para las mujeres afrocubanas y blancas, respectivamente.

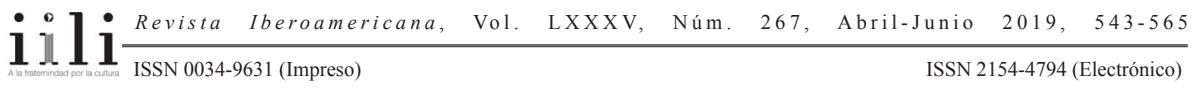


Sin embargo, la educación superior y la inserción en el mercado laboral son los diferenciales más acusados entre mujeres blancas y afrocubanas. Como refiere Ramírez "si bien el 10\% de todas las empleadas afrocubanas se introdujeron en la industria, los empleos públicos y la empresa, el 67,5\% continuaba trabajando en oficios manuales relacionados con la agricultura o los servicios domésticos" (Ramírez 818). La segregación de mujeres afrocubanas en ciertos sectores laborales, empujadas en gran medida por la imposibilidad de cursar estudios superiores en un sistema universitario restrictivo y con escaso apoyo institucional en forma de becas, sugiere la existencia de la discriminación racial como un hecho naturalizado. Pérez argumenta que el efecto más pernicioso de la presencia estadounidense fue precisamente el grado de respetabilidad en la vida diaria con el que se manejaban las discriminaciones raciales (Pérez 323). En el caso de la mujer afrocubana no será hasta 1939, cuando en el marco del III Congreso Nacional de Mujeres, la participación afrocubana y la coyuntura política (auge del afrocubanismo durante la década de 1930 y antesala de la constitución de 1940) harán posible examinar la situación de las mujeres negras, estableciéndose una mesa que llevó por título La mujer y los prejuicios raciales donde se analizaron los siguientes temas:

1. Situación de la mujer negra en Cuba. Su problema social, cultural y económico.

2. El prejuicio racial y el niño. Igualdad del niño negro y el niño blanco.

3. Igualdad legal y real de las mujeres negras y blancas en la vida cubana.

4. Los prejuicios raciales y sus manifestaciones en el mundo: lucha contra ellos.

5. Participación de la raza negra en la formación de nuestra nacionalidad (Yáñez citado en Ramírez 814)

Una somera revisión de las portadas de Carteles confirma que la inclusión de la representación afrocubana responde a propósitos muy concretos y con un imaginario cultural muy definido con relación a la población afrocubana como son el exotismo, la infantilización o la asociación con la música. Por ejemplo en la portada del $10 \mathrm{de}$ abril de 1932, un grupo de personas dibujadas con rasgos caucásicos contemplan a un niño afrocubano que pasa por delante de ellos.

La representación de las repúblicas centroamericanas y caribeñas como niños (en gran medida, niños negros) fue por otro lado una metáfora constante en la prensa norteamericana de principios del siglo XX, como ha documentado Johnson, que incide en la visión de estos países como inmaduros y necesitados de una figura patriarcal, representada por los EE.UU. (Johnson 116). En esta portada de Carteles la composición de imagen incide en el niño afrocubano en primer término como agente de la acción y las personas adultas que lo contemplan, en segundo plano, como pacientes de la misma. Los adultos son turistas arribados a La Habana para disfrutar de una experiencia

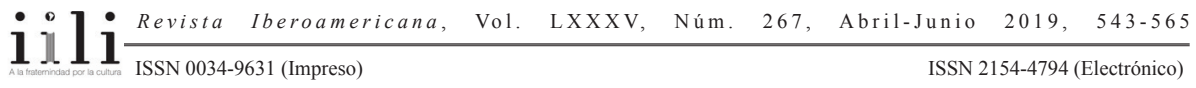




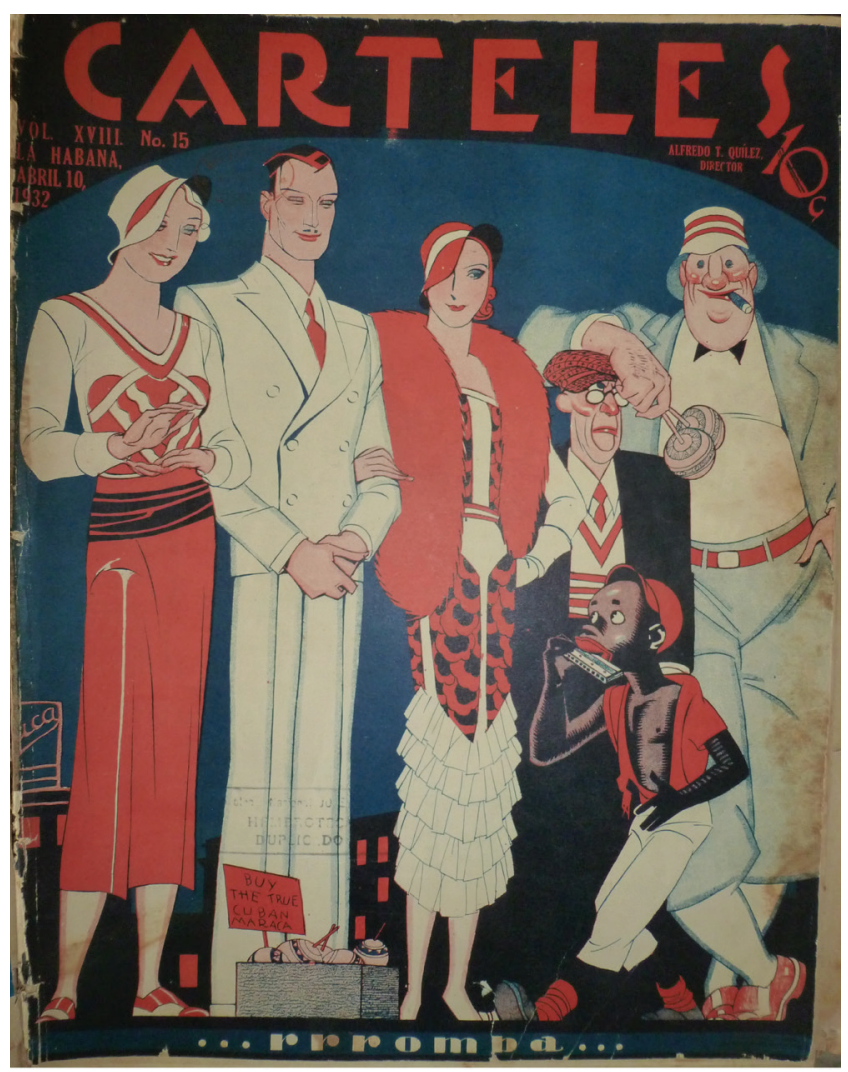

caribeña. ${ }^{6}$ Hay incluso un letrero en inglés que apela al comprador sobre la auténtica experiencia cubana: "Buy the true Cuban maraca". ${ }^{7}$ En este sentido Massaguer, autor de la portada, había sido nombrado presidente del Comité de Propaganda y Publicidad por el gobierno de Menocal tras aprobar la ley de turismo de 1919.

6 Similar portada se reproduce en el número de Social de julio de 1933, esta vez con una mujer afrocubana vendiendo calabazas en la calle a una pareja de turistas blancos.

7 En un artículo para Social titulado "Arte popular criollo" José Antonio Fernández de Castro recuerda la frase de Jorge Mañach (Cuba era un pueblo sin souvenirs) para incidir en la necesidad de revitalizar el arte popular criollo ya que antes de que se pusieran de moda las maracas, los turistas se llevaban mantones de Manila, castañuelas o abanicos con corridas de toros, importados de España o Filipinas: "Claro que el turista -ni todas las personas-, llegan fácilmente al íntimo rincón de nuestro pueblo, y no pueden ver los papalotes ingenuamente decorados con motivos tan típicamente afro-cubanos que empinan nuestros pillos por las azoteas" (Fernández de Castro 14).

11
11 


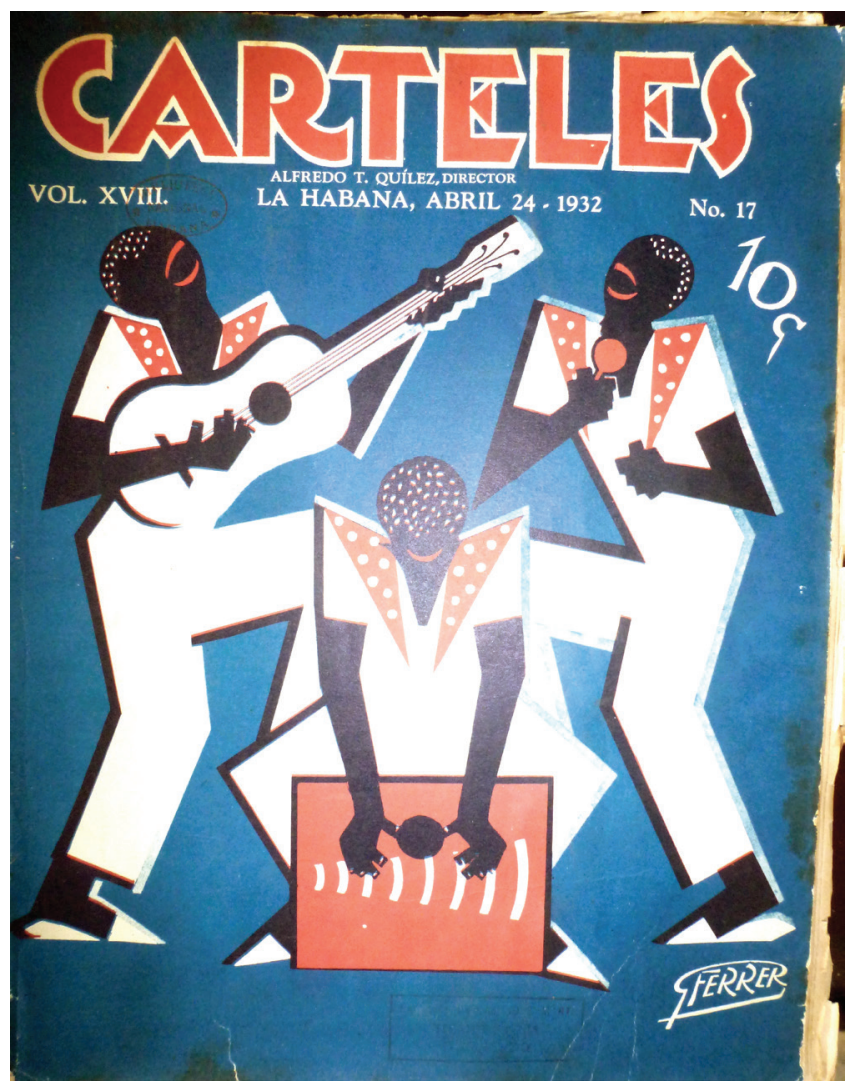

La portada del 24 de abril de 1932 presenta un trío musical afrocubano dibujado con formas geométricas a base de tiralíneas. El distanciamiento del dibujo recargado y la apuesta por una línea escueta que permita definir el objeto o la persona fueron algunas de las innovaciones formales en el dibujo introducidas en las revistas ilustradas de este periodo que buscaron con ello desmarcarse del estilo realista o caricaturesco (a base de la deformación exagerada) de publicaciones del siglo XIX como La Política Cómica (1894). Sobre este particular, Ricardo de la Torriente (1869-1934) fue el creador del Liborio para La Política Cómica, personaje humorístico de largas patillas que se convirtió en "testigo socarrón de la primera etapa de la república mediatizada" (Juan 11). El Liborio fue esencial para entender el paso de la colonia a la república cada vez más influida por los intereses de los Estados Unidos, lo que para Edmundo Desnoes significó aceptar "la imagen degradada que nos impuso la Metrópoli [...] Torriente, con dibujos chapuceros y siempre mediocres, insiste en esta imagen del cubano en $L a$

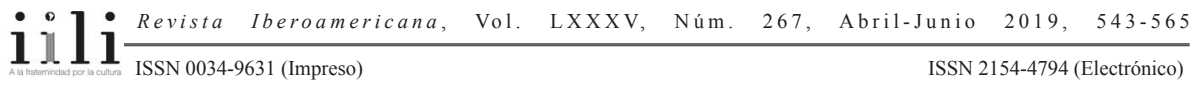


Política Cómica" (Desnoes 27). A nivel gráfico Ricardo de la Torriente representaba un modelo ya superado como señaló Bernardo Barros en 1916:

La técnica de este dibujante adolece de una errónea percepción de valores. A veces pretende sintetizar, sugerir, con dos o más rasgos mal combinados, la sensación de conjunto [...] Es además, uno de los pocos caricaturistas que hoy aceptan en Cuba el canon absurdo y totalmente desautorizado de la caricatura deformativa, la más fácil y la más cómoda para el artista que no quiere o no puede precisar la síntesis. (Barros citado en Juan 57)

La injerencia estadounidense en Cuba tenía cuerpo legal con la Enmienda Platt a la constitución cubana que otorgaba poderes a los Estados Unidos para intervenir en la Isla si lo estimaba oportuno. Con el cese de La Política Cómica en 1931, el fallecimiento de Torriente en 1934 y, por encima de todo, la abolición de la Enmienda Platt tras la caída de Machado y la nueva constitución de 1940, la primera etapa republicana llegaba a su fin en Cuba.

\section{José DOLORES, EL PROTOTIPO DEL FASTIDIADOR CUBANO}

La década de 1930 es de especial importancia por las crecientes discusiones que apuntaron hacia una mayor aceptación de la comunidad afrocubana, a la vez que significó un despegue en la prensa periódica en cuanto a la popularización de la gráfica del humor en forma de historieta nacional. Periódicos como El País comenzaron a sacar suplementos en los que se reproducían historietas norteamericanas a todo color, pero en los que también comenzaron a aparecer creaciones cubanas, como por ejemplo el cómic Napoleón, el faraón de los sinsabores, obra de Manuel Alonso García, que comenzó a publicarse el 15 de mayo de 1937. Esta obra fue además la base del primer cortometraje sonoro de animación (de apenas dos minutos de duración) que se estrenó en agosto de 1937 (Agramonte y Castillo 22-24). Entre las publicaciones de este periodo quiero llamar la atención sobre El Avance Criollo que comenzó a editar un suplemento sabatino titulado Revista Rosa en el que se publicaron cómics estadounidenses a todo color como "Tarzan", pero también historietas cubanas como "Buchito" de Silvio Fontanillas. ${ }^{8}$ Como era de esperar nuevos personajes afrocubanos hicieron su aparición en este contexto y en 1936 un joven artista, Rafael Fornés,

Silvio Fontanillas fue una figura importantísima en el humor gráfico cubano especialmente por su influyente tira de prensa para Bohemia "El reyecito criollo" durante la década de 1950. "El reyecito", inspirado en "The Little King" de Otto Soglow, ejerció de vocero de la situación socio-política en Cuba. También participó en la revista Zig-Zag hasta su cierre en 1960, año en el que se exilia Fontanillas yendo a los EE.UU. donde funda El Nuevo Zig-Zag, que se conserva en microfilm en The University of Florida.

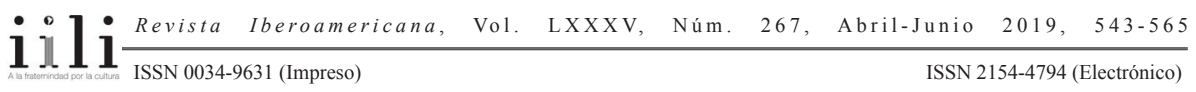


que posteriormente se convertiría en una referencia fundamental del humor gráfico cubano dirigiendo la vanguardista publicación El Pitirre (1960-1961), dio vida al personaje afrocubano José Dolores. En el ejemplo reproducido de septiembre de 1937, Fornés que escasamente tenía 20 años, celebró en una doble página el aniversario de su primera historieta: “José Dolores. La creación criolla”. La historieta en cuestión desarrolla una temática costumbrista con el elemento cómico al final de la misma como inesperado giro argumental (Catalá-Carrasco, "Costumbrismo" 496).

El propio Fornés se incluyó en el dibujo junto al famoso dramaturgo y periodista

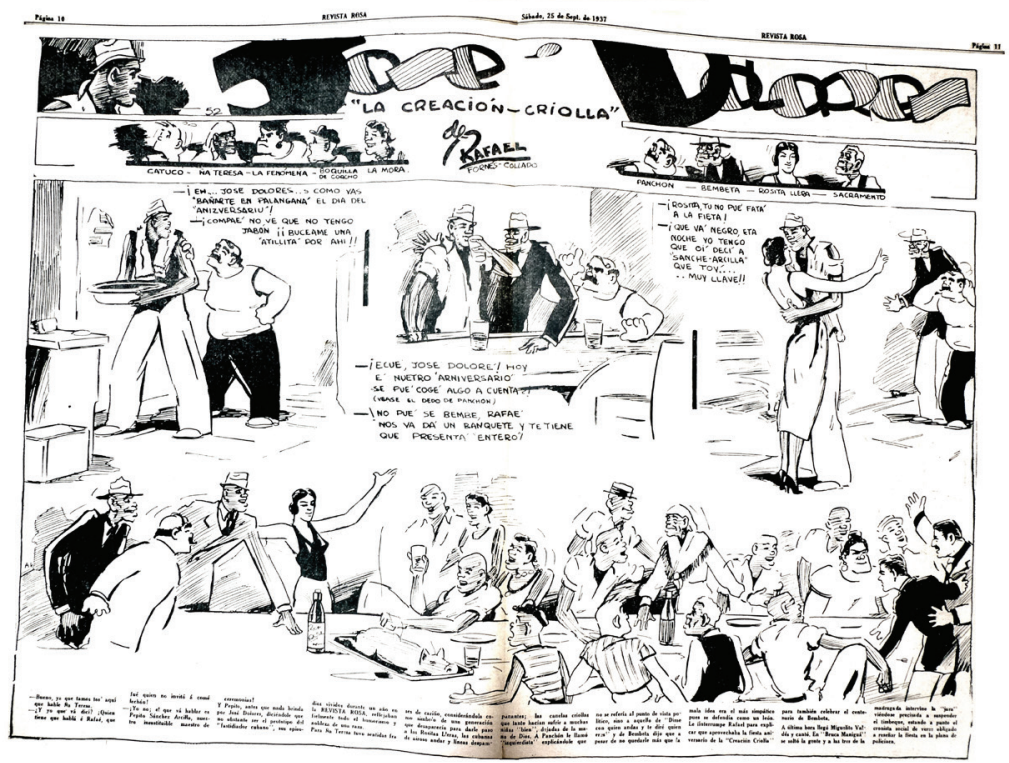

José Sánchez Arcilla, ${ }^{9}$ pionero de las radionovelas en Cuba (aparece junto a Fornés, luciendo bigote y corbata). Sánchez Arcilla (situado en el extremo derecho de la imagen) es el maestro de ceremonias del evento y brinda por José Dolores diciendo que "no obstante ser el prototipo del "fastidiador cubano", sus episodios vividos durante un año en la REVISTA ROSA, reflejaban fielmente todo el humorismo y la nobleza de una raza". La descripción de José Dolores sugiere que las acciones de este personaje son de sobra conocidas para la audiencia de la revista tras un año de publicación ininterrumpida. En realidad, José Dolores es una versión moderna del negro curro

9 Sánchez Arcilla fue también el co-autor del guion para la versión en zarzuela del clásico de las letras cubano Cecilia Valdés, que se estrenó en 1932 y hasta la fecha se considera uno de los mejores ejemplos del género.

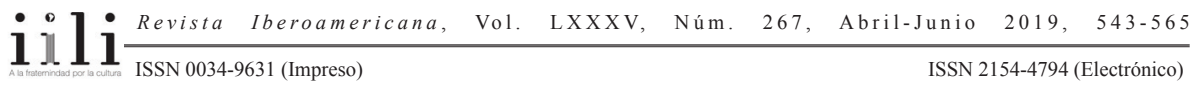


que según el antropólogo Fernando Ortiz fue un tipo social específicamente urbano: "El negro curro del Manglar fue un tipo propio de la ciudad de La Habana y de Regla y otros arrabales o pueblos suburbanos" (Ortiz, Los negros curros 13). Si bien el negro curro a principios del siglo XX había desaparecido como tipo social, persisten algunas de sus características que se trasladan a este personaje de historieta, como su vanidad, su jerga y su astuta habilidad para maniobrar en la ciudad. En definitiva, una combinación de viveza y choteo. En este sentido Ortiz declaró que "indudablemente, el negro curro de La Habana fue un pícaro, un sujeto de vida apicarada [... ] la picardía era una amplia manera de "vivir la vida"" (Ortiz, Los negros curros 35). En esta historieta José Dolores está más próximo al "guapo criollo" definido por Eladio Secades en una de sus estampas costumbristas de 1941 como "matón, belicoso, respetado por los cobardes. Que camina de medio lado" (Secades 29).

El narrador de la escena dibujada a doble página también se refiere a dos mujeres afrocubanas del banquete: "Para Na Teresa tuvo sentidas frases de cariño, considerándola como símbolo de una generación que desaparecía para darle paso a las Rositas Lleras las cubanas de airoso andar y líneas despampanantes; las canelas criollas que tanto hacían sufrir a muchas niñas 'bien' dejadas de la mano de Dios”. Na Teresa y Rosita Llera son representantes de dos sociedades próximas en el tiempo pero distantes a tenor de los cambios que había experimentado la joven república en sus escasos 30 años de existencia. Ña Teresa representa el antiguo régimen colonial por su avanzada edad y su manera de comportarse y vestir, mientras que Rosita Llera, nacida ya con la República, encarna los nuevos tiempos modernos en Cuba.

Alrededor de la mesa, los negros y mulatos dominan la escena. Los personajes afrocubanos no son solamente visibles en este cómic sino que son los protagonistas. Esta historieta costumbrista nos ofrece una visión de la Cuba de la década de 1930 desde una perspectiva popular en la que un joven artista refleja lo que oye y ve (la oralidad del lenguaje es una de las características principales de la historieta) en las calles y solares más humildes de La Habana.

El momento era propicio para la visibilidad y el reconocimiento de los afrocubanos, ya que por primera vez la Cuba criolla blanca estaba redescubriendo y reapropiándose de la Cuba negra como un elemento central de la nacionalidad cubana. A través de la música primero en la década de 1920 y plenamente en los años treinta a través del movimiento afrocubanista (Pignot). Rápidamente permeó en la literatura, la antropología y las artes visuales, alejándose de la supuesta ausencia de racismo oficial y los prejuicios que categorizaban a los afrocubanos como atávicos y subdesarrollados hacia una actitud hasta cierto punto más inclusiva, dentro de unas estructuras propiamente racistas.

Quien mejor ejemplifica este cambio es el polígrafo Fernando Ortiz, que partiendo de un positivismo influido por el pensamiento lombrosiano, publicó un primer estudio, Los negros brujos (1906), sobre las supervivencias religiosas y mágicas de

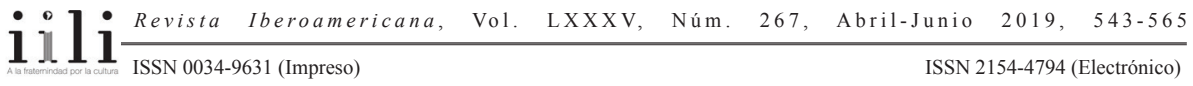


las culturas africanas en Cuba. En dicho libro Ortiz acuñó el vocablo afrocubano, "palabra que ya había sido empleada en Cuba una vez en 1847, por Antonio de Veitia [...] pero no había cuajado en el lenguaje general como lo está hoy día" (Ortiz, "Por la integración" 53-54). Ortiz paulatinamente centró sus investigaciones en las prácticas culturales, en lugar de en la raza, iniciando los estudios sobre cultura afrocubana. Asimismo, los debates sobre raza en la prensa periódica los lideró Gustavo Urrutia en la década de 1930 con su columna para Diario de la Marina, "Ideales de una raza", que comenzó en 1928. A estos debates se sumó la poesía de Nicolás Guillen, ya en la década de 1920 hasta que publicó su primer libro de poemas, Motivos de son, en 1930. Por su lado, Alejo Carpentier publicó su primera novela, Eccue-Yamba-O (1933) con protagonismo afrocubano.

La sociedad percibía un cambio en la visibilidad de la cultura afrocubana entre la prohibición de toda ceremonia o danza de carácter afrocubano en 1922 (Fuente 51) y la resolución del dictador Gerardo Machado declarando la muerte de Antonio Maceo (héroe afrocubano de la independencia) como fiesta nacional en 1930. A lo largo de los años 20 y 30 los cubanos negros se convirtieron en una entidad política, coincidiendo con el periodo de Machado en el gobierno (1925-1933), aunque la captación del voto negro había comenzado justo después de la derrota de España en 1898, con los interminables banquetes que honraban a los veteranos negros.

La lucha por una representación alternativa de la cultura afrocubana como primitiva o inferior estuvo, por ejemplo, en el centro de las discusiones sobre las festividades de carnaval y la prohibición de las comparsas. En enero de 1937 el alcalde de La Habana pidió a la Sociedad de Estudios Afrocubanos si era aconsejable permitir la actuación de las comparsas como parte de las Fiestas del Carnaval. Con la esperanza de levantar la prohibición, la Comisión de Turismo recomendó la inclusión de las comparsas esperando que los turistas llegaran para disfrutar de este espectáculo de cultura tradicional (Bronfman 159). Nueve comparsas desfilaron por las calles (Los Mambises, Los Guaracheros, Los Modernistas, etc) y este hecho es precisamente el que se reproduce en el ejemplo de la historieta "José Dolores" del 6 de marzo de $1937 . .^{10}$

${ }^{10}$ El 28 de mayo de 1937 El País incluyó un artículo del actor, cantante y activista por los derechos civiles en los EE. UU. Paul Robeson titulado "Las riquezas de la cultura del negro" en el que expresaba un cambio en la mentalidad de las sociedades respecto al negro: "Ha pasado el día en que eran considerados por los blancos como algo menos que seres humanos y algo más que meros salvajes. La tolerancia racial y la igualdad de status político han ocupado el lugar de la opresión y la esclavitud para la mayor parte de la raza negra" (Robeson s/p).

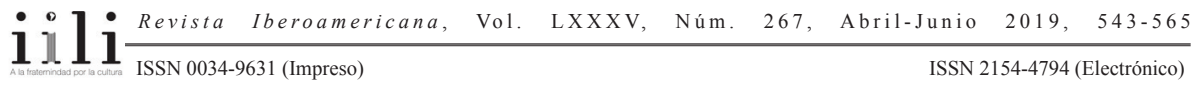




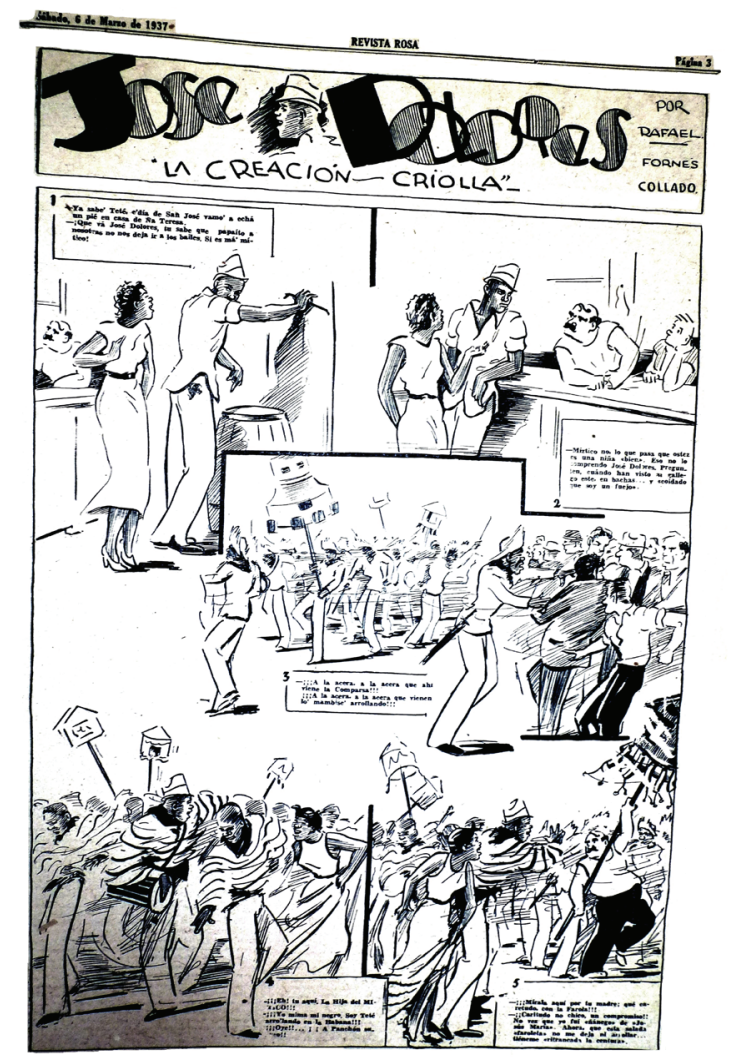

La reinstauración de las comparsas contó con la recomendación de personas de renombre como Fernando Ortiz o Emilio Roig de Leuchsenring y abrió el debate sobre la política de la representación, como ha sugerido Bronfman: "To what extent did paternalistic state-sponsored displays of those practices detract from the realities of persistent social and economic inequality? Who ought to control the representation of cultures?" (Bronfman 161). Los críticos de las comparsas argüían que la desigualdad social era rebajada y de alguna manera incluso reproducida por estas prácticas de las tradiciones africanas como espectáculos estereotipados que buscaban la apelación al exotismo. Como tales eran un obstáculo para la igualdad social plena que debe acompañar el ejercicio de la ciudadanía. Esta situación cambió notablemente en el marco legal con la nueva constitución de 1940 en la que expresamente se declaró ilegal y penable toda discriminación basada en raza, color, sexo y religión. Sin embargo, la puesta en práctica del código legal distó mucho de ser eficiente y la desigualdad

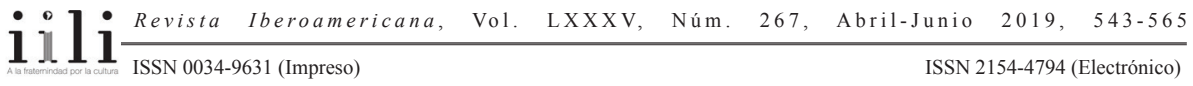


pervivió ya que muchas de las medidas propuestas no fueron implementadas con el suficiente rigor.

\section{CONCLUSIÓN}

Con todas las debidas reservas ante una tácita y complaciente aceptación de la cultura popular como manifestaciones que emanan desde abajo y teniendo en cuenta que la vieja distinción binaria entre cultura popular y cultura masiva "which depends on the existence of the 'mass' as the subject of (ideological) interpellation through hierarchical and one-way media programming, has increasingly been rendered inoperative" (Kantaris y O’Bryen 17), el rápido desarrollo de los medios de masas en Cuba (en particular la prensa ilustrada de principios del siglo XX), representa un terreno fértil en el que ahondar en el entendimiento y la representación de la afrocubanía. En las publicaciones periódicas leemos sobre la conflictiva negociación de las narrativas heroicas sobre la participación de los afrocubanos en la lucha por la independencia a finales del siglo XIX combinado con los temores prejuiciados de atavismo y la omnipresente influencia lombrosiana sobre criminología que categorizó a los afrocubanos como primitivos y bárbaros a principios del siglo XX. ${ }^{11}$ Se puede por lo general distinguir entre un paradigma más restrictivo en cuanto a comportamiento, roles y profesiones asignados a los afrocubanos con el cambio de siglo hacia una más expansiva (hasta cierto punto inclusiva) visión de los afrocubanos en el proceso de la construcción nacional, tras la brutal represión contra el Partido Independiente de Color en 1912 y la consolidación de los afrocubanos como una entidad política con la administración de Machado en la década de 1920 y principios de 1930.

El impulso democrático de la cultura visual (tal y como lo ha expresado Martin Jay $^{12}$ ) significa que podemos acercarnos a manifestaciones como el humor gráfico o los cómics no solamente como posibles representaciones de la identidad nacional en constante negociación entre el artista, el medio, la audiencia y el contexto, sino como una producción cultural que llega a su madurez gracias a la modernidad y es, en cierto sentido, una representación cultural de la misma. La moderna tira cómica de prensa, la narración de historias a través de imágenes en secuencia es un medio originalmente concebido para su reproducción, es decir, es un medio de masas. Los

${ }_{11}$ Uno de los entrevistados por Reynaldo González en su libro testimonial La fiesta de los tiburones (1978) refleja los prejuicios y el miedo al negro durante la rebelión de 1912 del Partido Independiente de Color: "Lo de las violaciones se puso de moda. La gente traía un alboroto tremendo y algunas blancas racistas veían negros desnudos hasta en sueños" (González 83).

12 "By democratization, I simply meant the growing willingness to take seriously as objects of scholarly inquiry all manifestations of our visual environment and experience, not only those that were deliberately created for aesthetic effects or have been reinterpreted in formalist terms growing willingness to take seriously" (Jay 183).

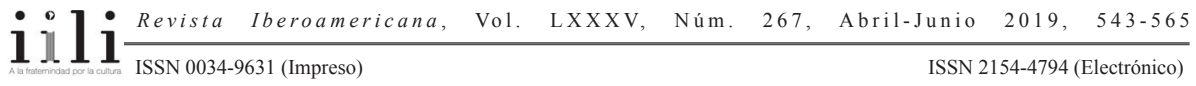


cómics pertenecen a la familia de los medios de masas, ya que es en los periódicos, las revistas ilustradas y los suplementos culturales orientados a un público adulto donde las tiras cómicas comenzaron a desarrollarse en el siglo XIX. De hecho, lo que distingue a la historieta de otras narrativas gráficas es la prevalencia (o incluso la imposición) de una narrativa secuencial para estructurar las historias. El entendimiento de que existe una narrativa interna entre las viñetas, que existe un antes y un después, lleva el signo de la modernidad de dos maneras. Por un lado supone una ruptura con la visión eterna de carácter religioso del tiempo. Ese continuo se rompe en escenas mundanas o capítulos de la existencia humana. Pero por otro lado, también es la comprensión de la vida como una secuencia de acciones o momentos en progreso de los cuales no podemos escapar.

Es por lo tanto necesario que para ulteriores estudios acerca de la visualización afrocubana y la desigualdad social en la Cuba de principios de siglo XX, los investigadores que trabajamos la cultura visual miremos más allá de las vanguardias pictóricas de la década de 1920. En este sentido, la producción cultural de carácter efímero contenida en la prensa periódica compuesta de revistas, periódicos y folletos ( $\mathrm{u}$ otras manifestaciones de la cultura popular como las comparsas) presentan un material que ineludiblemente debe entrar en diálogo con aquellas manifestaciones culturales pertenecientes al canon. El costumbrismo que presentan muchas de estas manifestaciones efímeras, algunas de ellas escasamente estudiadas como la historieta de estos años, es un material valioso en el que se condensan las narrativas de aceptación y rechazo del afrocubano, no como categorías claramente diferenciadas, maniqueas en última estancia, sino en cuanto "trama, entrelazamiento de sumisiones y resistencias, de impugnaciones y complicidades” (Martín-Barbero 201).

\section{BiBLIOGRAFÍA}

Agramonte, Arturo y Luciano Castillo. Cronología del cine cubano II (1937-1944). La Habana: ICAIC, 2012.

Alemán Ruiz, Antonio. "Un factor del progreso: la prensa gráfica”. Bohemia 3 oct. 1915: s/p.

Álvarez Pitaluga, Antonio. La familia de Máximo Gómez. La Habana: Editora Política, 2008.

Aramburu, Diana. "Las fiestas afrocubanas en las marquillas cigarreras del siglo XIX: El Almanaque profético para el año 1866". Afro-Hispanic Review 29/1 (2010): 11-34.

Bermúdez, Jorge R. Massaguer. República y vanguardia. La Habana: Centro Cultural Pablo de la Torriente Brau, 2011.

Bronfman, Alejandra. Measures of Equality Social Science, Citizenship, and Race in Cuba, 1902-1940. Chapel Hill: The U of North Carolina P, 2004.

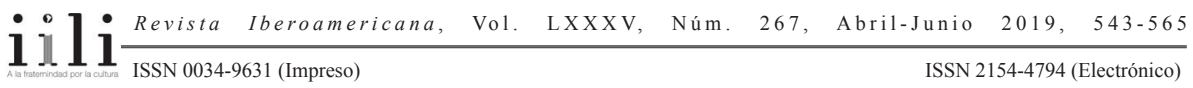


Catalá-Carrasco, Jorge L. “Costumbrismo and cubanity in Rafael Fornés”. International Journal of Comic Art 10/2 (2008): 495-518.

Paulo Drinot y James Scorer. Comics and Memory in Latin America. Pittsburgh: Pittsburgh UP, 2017.

Desnoes, Edmundo. "El humorismo en nuestra historia. Visión de la isla". Bohemia 29 ene. (1965): 26-28.

Diccionario de la literatura cubana. Tomo I. La Habana: Letras Cubanas, 1980.

"La Exposición Portell Vilá". Carteles. 21 feb. 1932: 23.

Fornés, Rafael. “José Dolores”. Revista Rosa supl. El Avance Criollo. 6 mar. 1937: 3 “José Dolores”. Revista Rosa supl. El Avance Criollo. 25 sept. 1937: 11.

Fornet, Ambrosio. El libro en Cuba. La Habana: Letras Cubanas, 2002.

Fuente, Alejandro de la. Nation for All. Chapel Hill: The U of North Carolina P, 2001.

González, Reynaldo. La fiesta de los tiburones. 1978. La Habana: Editorial de Ciencias Sociales, 2001.

Gordon, Ian. Comic Strips and Consumer Culture. 1890-1945. Londres: Smithsonian, 1998.

Hall, Stuart. "Notes on Deconstructing 'the Popular"'. Cultural Theory and Popular Culture. A Reader. John Storey, ed. Harlow: Pearson / Prentice Hall (1998): 44253.

Horacio. "Mango Macho". Carteles 11 dic. 1932: s/p.

Iglesias Utset, Marial. Las metáforas del cambio en la vida cotidiana: Cuba, 18981902. La Habana: Unión, 2003.

Jay, Martin. "That Visual Turn: The Advent of Visual Culture". Visual Culture Studies. Interviews with Key Thinkers. Marquard Smith, ed. Los Angeles: Sage (2008): 182-88.

Johnson, John J. Latin America in Caricature. Austin: U of Texas P, 1993.

Juan, Adelaida de. Caricatura de la república. La Habana: Unión, 1999.

Kantaris, Geoffrey y Rory O'Bryen. Latin American Popular Culture. Politics, Media, Affect. Woodbridge: Tamesis, 2013.

"Lexington". El Mundo. 30 sept. 1918: XVII.

Lobo Montalvo, María Luisa et. al. "The Years of 'Social"”. The Journal of Decorative and Propaganda Arts, Vol. 22, Cuba Theme Issue (1996): 104-31.

Lugo-Ortiz, Agnes. "Material Culture, Slavery and Governability in Colonial Cuba. The Humorous Lessons of the Cigarette Marquillas". No Laughing Matter: Visual Humor in Ideas of Race, Nationality, and Ethnicity. Angela Rosenthal y otros, eds. Lebanon: UP of New England, 2015. 118-146.

Massaguer, Conrado W. "Niño afrocubano" portada Carteles 10 abril 1932.

Mañach, Jorge. Estampas de San Cristóbal. 1926. La Habana: Ediciones Ateneo, 2000. Marble, Annie Russell. "The Reign of the Spectacular”. Arguing Comics. Literary Masters on a Popular Medium. Jeet Heer y Kent Worcester, eds. Jackson: UP of

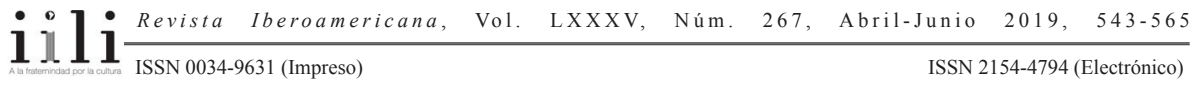


Mississippi, 2004. 7-8.

Martín-Barbero, Jesús. De los medios a las mediaciones. Comunicación, cultura y hegemonía. Barcelona: Gustavo Gili, 1998.

Merino Acosta, Luz. "La caricatura política". Figures, Genres et Stratégies de L'Humour en Espagne et en Amérique Latine. Yves Aguila, ed. Bourdeaux: Presses Univ. Bordeaux (2007): 63-68.

Moore, Robin D. Nationalizing Blackness: Afrocubanismo and Artistic Revolution in Havana, 1920-40. Chicago: U of Pittsburgh P, 1997.

Ortiz, Fernando. "Por la integración cubana de blancos y negros". Cultura cubana del siglo XX. Tomo I. La Habana: Félix Varela (2006): 53-59.

Los negros curros. La Habana: Editorial de Ciencias Sociales, 1995.

Pérez, Louis A., Jr. On Becoming Cuban. Identity, Nationality, and Culture. Chapel Hill: The U of North Carolina P, 1999.

Pignot, Elsa. "El asociacionismo negro en Cuba: una vía de integración en la sociedad republicana (1920-1960)". Revista de Indias LXX/250 (2010): 837-62.

Ramírez Chicharro, Manuel. "Doblemente sometidas: las 'mujeres de color' en la república de Cuba (1902-1959)”. Revista de Indias LXXIV/262 (2014): 783-827.

Robeson, Paul. "Las riquezas de la cultura del negro". El País 28 mayo 1937: s/p.

"Sanogyl dentífrico". Carteles. 22 mayo 1932: 63.

Secades, Eladio. Estampas (1941-1958). La Habana: Unión, 2010.

Valer, Pedro. "Aventuras de Pepito y Rocamora". Bohemia 17 oct. 1915: s/p.

Palabras clave: historieta, afrocubano, nación, modernidad

Recibido: $\quad$ junio 2016

Aprobado: $\quad$ septiembre 2018

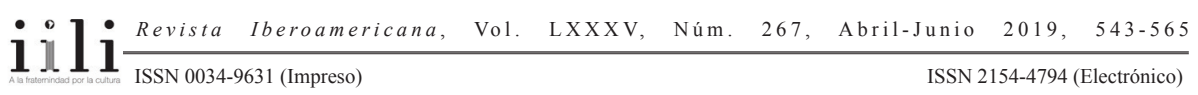


